\title{
Yeni doğan dudak damak yarıklı bebeklerin alçı modellerinin değerlendirilmesi
}

\author{
Merve Göymen ${ }^{1}$, Eren İşman ${ }^{1}$, Rıdvan Okşayann ${ }^{1}$, Tolga Topçuoğlu ${ }^{1}$
}

Selcuk Dental Journal, 2014; 1: 7-13

Basvuru Tarihi: 14 Mayıs 2013 Yayına Kabul Tarihi: 13 Aralık 2013

\section{The cast model evaluation of cleft and palate infants}

Background: Cleft Lip and Palate (CLP) is one of the most common congenital malformations in craniofacial area. In this study sex, age, anterior cleft width, midpalatal and posterior palatal width values were evaluated in CLP patients who referred to Orthodontic Department of Gaziantep University, Dentistry Faculty.

Methods: In this study 39 CLP patients' records were examined. Age, gender and cleft types of the patients were evaluated and measurements were performed on the cast models. $C$ and c' (canine area), $\mathrm{t}$ and t' (tuber area), $\mathrm{mp}$ and $\mathrm{mp}$ ' (middle alveolar arch width at half the distance between $C$ and $T$ points) were used as reference points. Descriptive statistics were done using SPSS V.19.0.

Results: Bilateral cleft patients were $24 \%$ of overall CLP patients. Isolated palate cleft patients were $20 \%$ and unilateral cleft $\% 56$ of overall CLP patients. In bilateral cleft patients group average age was $24.33 \pm 24.69$ days, $\% 66.7$ of group (6 patients) were boys, average of anterior cleft width $13.23 \pm 3.06$, midpalatal width $32.67 \pm 3.58$, postpalatal width $29.25 \pm 2.78 \mathrm{~mm}$. In isolated palate cleft patients group average of age $68.37 \pm 58.04$ days, $\% 37.5$ of group (3 boy) were boys, average of anterior cleft width $0 \mathrm{~mm}$, midpalatal width $30.71 \pm 2.11 \mathrm{~mm}$, postpalatal width $27.17 \pm 2.42 \mathrm{~mm}$. In unilateral cleft patients group average of age $31 \pm 30.11$ days, $\% 54.5$ of group (12 boy) were boys, average of anterior cleft width $10.14 \pm 3.12 \mathrm{~mm}$, midpalatal $35.74 \pm 3.05 \mathrm{~mm}$, postpalatal width $31.35 \pm 3.22 \mathrm{~mm}$.

Conclusion: Unilateral and bilateral clefts were most common in boys. Isolated palate cleft were most common in girls. Anterior cleft width was most common in bilateral cleft. Midpalatal and posterior palatal widths were most common in unilateral cleft patients. The age of application was lower in bilateral cleft patients than unilateral patients. Patients who applied our clinic were treated with Hotz plate or nasal molding appliances, and we will make a long term follow-up to compare the initial and posttreatment values.

\section{KEY WORDS}

Cleft lip, cleft plate, orthodontics
Dudak damak yarığı orta yüzde konjenital defektle karakterize konjenital bir malformasyondur. (Cornel ve ark 1988) DDY hastalarının rehabilitasyonu özellikle fonksiyonel ve estetik olarak oldukça önem taşır ve son derece özenli ve dikkatli bir tedaviyi gerektirir (Sokucu ve ark 2008). Beyaz irk populasyonunda dudak yarığı, damak yarığı veya her ikisinin birlikte görülme sıklığı bin doğumda 1.2 ila 1.6 arasında değişmektedir. Olguların \%20-30 u dudak yarıklı, \%35-50 si dudakdamak yarıklıdır (Shah ve ark 1980). Yeni doğanlardaki yarığın boyutu yapilacak operasyonu ve buna bağlı olarak operasyon sonrası tedavi sonuçlarını indirekt olarak etkilemektedir. (Reiser 2011) Yarık boyutunun tedavi sonuçlarını etkilediği ile ilgili birçok çalışma mevcut olup ark boyutu ve okluzyon (Hellquist ve ark 1976, Heliovaara ve ark 1994), maksiler büyüme (Liao ve ark 2010, Chiu ve ark 2011) ve fonasyon (Persson ve ark 2002) ile olan ilişkisi gösterilmiştir. Johnson ve ark. (2000) tek taraflı dudak damak yarıklı yeni doğan hastalarında yaptıkları çalışmada yarık alanının toplam palatal alana oranını ölçmüşler. Yapılan longitudinal çalışmada bireylerin 6 yaşında okluzal indeksleri oluşturulmuş ve başlangıç defekt boyutu ile okluzal indeks

\footnotetext{
${ }^{1}$ Gaziantep Üniversitesi Diş Hekimliği Fakültesi Ortodonti Anabilim Dalı
} 
arasında anlamlı bir ilişki bulunmamıştır.

Peltomaki ve ark. (2001) yaptıkları retrospektif çalışmada tek taraflı dudak damak yarıklı hastaların infant ölçüleri ile 6 yıllık takip sonu sefalometrik değerlerini karşılaştırmışlardır. Çalışma sonuçlarına göre başlangıç yarık boyutu fazla olup kısa ark uzunluğuna sahip olan hastalardaki maksiler büyüme, az yarık genişliği ve uzun ark boyuna sahip olan hastalara göre daha az olmuştur.

Reiser ve ark. (2010) tek taraflı dudak damak yarıklı ve damak yarıklı hastalarda yaptıkları çalışmada tek taraflı dudak damak yarıklı hasta grubunda diğer gruba göre çapraz kapanış miktarının daha fazla olduğunu tespit etmişler.

Lohmander-Agarskov ve ark. (1997) sert damaktaki rezidüel yarık genişliğinin konuşmayı etkilediğini göstermişlerdir. Perrson ve ark. (2002) damak yarıkı çocuklardaki yarık genişliğinin oral artikülasyonla ilişkili olduğunu bulmuşlar.

$\mathrm{Bu}$ alanda birçok çalışma yapılmış olmasına rağmen Gaziantep ve çevresini içeren bölge kapsamında tek ya da çift taraflı dudak damak yarıklı ve damak yarıklı yeni doğan hastalarını kapsayan bir çalışma bulunmamaktadır. Bu çalışmanın amacı Gaziantep Üniversitesi Diş Hekimliği Fakültesi Ortodonti bölümüne başvuran yeni doğan dudak damak yarıklı hastalardaki yarık miktarı ve cinsiyet dağılımının belirlenmesidir.

\section{GEREÇ ve YÖNTEM}

Çalışmaya Gaziantep Üniversitesi Diş Hekimliği Fakültesi Ortodonti A.D a başvuran tek ya da çift tarafı dudak-damak yarıkları ile izole damak yarığı bulunan 39 yenidoğan hasta dahil edilmiştir. Hastaların ölçüsü silikon ölçü maddesi (Zhermack Zetaplus, Badia Polesine, Italy) kullanılarak alınmıştır. Gerekli olduğu durumlarda ikincil ölçü maddesi kullanılmıştır. Ölçü alma işlemi sırasında bebek veli ve doktorun kucağında yatar vaziyette konumlandırılmıştır. Elde eldilen alçı modeller aracılığıyla akrilik materyalden pasif beslenme plağı yapılmıştır. Ve plak mukozal irritasyona sebep olmaması için hasta ağzına uyumlanmıştır.

Yarık boyutu ile ilgili 1995'te Honda ve arkadaşlarının (Honda ve ark 1995) ve yine ayn yılda Seckel ve arkadaşlarının (1995) yaptıkları başka bir çalışmada direk ölçü modellerinin üzerinden digital ölçüm yapılmıştır. Sillman (1964) çalışmasında ölçüm yaparken belirlediği noktalar Barbara ve ark. (2006) çift taraflı dudak damak yarığı olgularında yaptığı başka bir çalışmada da kullanılmıştır. Bizim bu çalışmamızda ölçüm yaparken de benzer referans noktaları kullanılmıştır. Bu noktalar tek tarafı dudak damak yarıklı (Şekil 1), izole damak yarıklı (Şekil 2) ve çift taraflı dudak damak yarıklı (Şekil 3) bireyler için tanımlanmıştır.

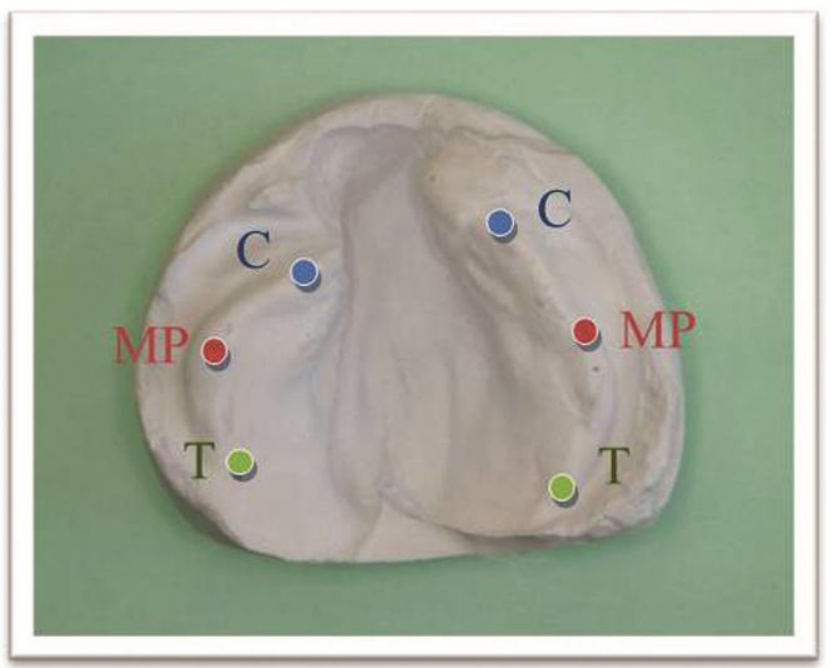

Şekil 1.

Tek taraflı dudak damak yarıklı yeni doğan modelinde kullanılan referans noktaları: $\mathrm{C}$ noktası; kanin noktası MP; midpalatal nokta. Yarık segmentin orta noktası T noktası; tüber noktası

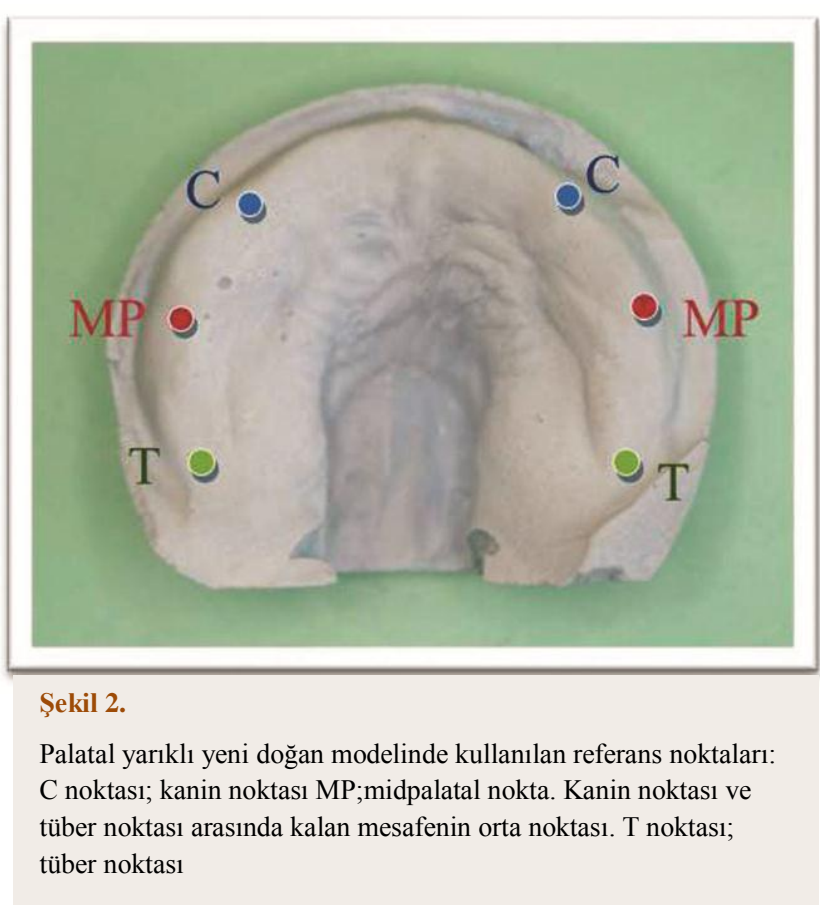




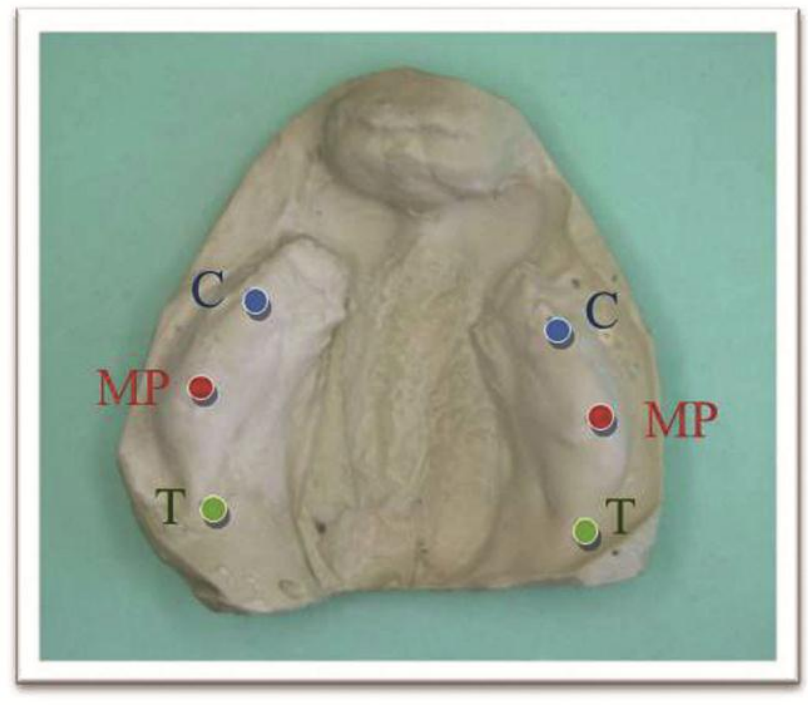

Şekil 3.

Çift taraflı dudak damak yarıklı yeni doğan modelinde kullanılan referans noktaları; C noktası; kanin noktası MP noktası; midpalatal nokta. Yarık segmentin orta noktası. T noktası; tüber noktası.

Verilerin istatiksel değerlendirilmesi için SPSS for Windows version 11,5 paket programı kullanılmış ve $\mathrm{P}<0.05$ istatistiksel olarak anlamlı kabul edilmiştir. Sürekli değişkenlerin normal dağılıma uygunluk kontrolünde Kolmogorov Smirnov testi kullanılmıştır. 2 bağımsız grup karşılaştırılmasında normal dağılıma sahip olmayan değişkenler için Mann Whitney U Testi kullanılmıştır. 2 den fazla bağımsız grup karşılaştırılmasında Kruskal Wallis testi ve Dunn çoklu karşılaştırma tesleri kullanılmıştır. Kategorik değişkenler arasındaki ilişki ki-kare analizi ile test edilmiştir.

\section{BULGULAR}

Çalışmada değerlendirilen bireylerin (39 kişi) \%24 ü (9 kişi) çift taraflı dudak damak yarıklı, \%20 si (8 kişi) izole damak yarıkl, \%56sı (22 kişi) ise tek tarafı dudak damak yarıklı yeni doğan hastadır. Çift taraflı dudak damak yarığı bulunan grubun yaş ortalaması $24.33 \pm 24.69$ gün dür. Bu grubun $\% 66.7$ si (6 kişi) erkektir. Ortalama anterior yarık genişliği 13.23 \pm 3.06 , midpalatal yarık genişliği $32.67 \pm 3.58$, postpalatal yarık genişliği $29.25 \pm 2.78 \mathrm{~mm}$ dir. İzole damak yarı̆̆ı bulunan grubun yaş ortalaması $68.37 \pm 58.04$ gün dür. Bu grubun \% 37.5 si (3 kişi) erkektir. Ortalama anterior yarık genişliği $0 \mathrm{~mm}$, midpalatal yarık genişliği $30.71 \pm 2.11 \mathrm{~mm}$, postpalatal yarık genişliği $27.17 \pm 2.42$ $\mathrm{mm}$ dir. Tek taraflı dudak damak yarığı bulunan grupta yaş ortalaması $31 \pm 30.11$ gündür. Bu gruptaki bireylerin \%54.5i (12 kişi) erkektir. Ortalama anterior yarık genişliği $10.14 \pm 3.12 \mathrm{~mm}$, midpalatal yarık genişliği $35.74 \pm 3.05 \mathrm{~mm}$, posterior yarık genişliği $31.35 \pm 3.22 \mathrm{~mm}$ dir.

Medyan anterior yarık genişliği miktarı; çift tarafı dudak damak yarığı grubunda $12,00[11,00-15,9]$, tek taraflı dudak damak yarığı grubunda 10,90[8,00$12,23] \mathrm{mm}$ dir. Medyan midpalatal yarık genişliği miktarı; çift taraflı dudak damak yarığı grubunda $32,20[30,80-34,85]$, izole damak yarı̆̆ grubunda $31,90[28,27-32,40]$, tek taraflı dudak damak yarığı grubunda ise $35,75[34,52-38,12] \mathrm{mm}$ dir. Medyan posterior yarık genişliği miktarı; çift taraflı dudak damak yarığı grubunda 29,30[27,25-31,50], izole damak yarığı grubunda $27,00[25,25-28,10]$, tek taraflı dudak damak yarı̆ı grubunda ise $32,00[28,82-33,32]$ mm olarak bulunmuştur (Tablo 1).

Tablo 1.

Verilerin istatistiksel analiz sonuçları

\begin{tabular}{|c|c|c|c|c|c|}
\hline Değişkenler & & $\begin{array}{l}\text { Çift Taraflı Yarık } \\
\text { Grubu }(n=9)\end{array}$ & $\begin{array}{l}\text { İzole Damak Yarığı } \\
\text { Grubu }(n=8)\end{array}$ & $\begin{array}{l}\text { Tek Taraflı Yarık } \\
\text { Grubu }(n=22)\end{array}$ & $\mathbf{P}$ \\
\hline Cinsiyet & $\mathrm{K} \mathrm{Iz}$ & $3(33,3)$ & $5(62,5)$ & $10(45,5)$ & \multirow{2}{*}{0,478} \\
\hline Sayı(\%) & Erkek & $6(66,7)$ & $3(37,5)$ & $12(54,5)$ & \\
\hline Yaş (gün) * & & $24,33 \pm 24,69$ & $68,38 \pm 58,04$ & $31,00 \pm 38,93$ & 0,098 \\
\hline $\begin{array}{l}\text { Anterior } \\
\text { yarık genişliği }(\mathrm{mm})^{\star *}\end{array}$ & & $12,00[11,00-15,9]$ & -------- & $10,90[8,00-12,23]$ & $0,047 \ddagger$ \\
\hline $\begin{array}{l}\text { Midpalatal } \\
\text { yarık genişliği }(\mathrm{mm}) \text { ** }\end{array}$ & & $32,20[30,80-34,85]$ & $31,90[28,27-32,40]$ & $35,75[34,52-38,12]$ & $0,001 \ddagger$ \\
\hline $\begin{array}{l}\text { Posterior } \\
\text { yarık genişliği }(\mathrm{mm}) \text { ** }\end{array}$ & & $29,30[27,25-31,50]$ & $27,00[25,25-28,10]$ & $32,00[28,82-33,32]$ & $0,016 \neq$ \\
\hline $\begin{array}{l}\text { * (Ort } \pm \text { Std.sapma) } \\
\text { **Medyan[\%25-\%75] } \\
\neq \mathrm{p}<0,05\end{array}$ & & & & & \\
\hline
\end{tabular}


Anterior yarık genişliği miktarı karşılaştırılan iki grup (çift taraflı dudak damak yarığı ve tek taraflı dudak damak yarığı) arasında istatistiksel olarak anlamlı fark bulunmuştur. $(p<0.05)$ Çift taraflı dudak damak yarığı bulunan gruptaki bireylerin anterior genişlik miktarı tek taraflı dudak damak yarığı bulunan gruptaki bireylere göre anlamlı derecede yüksektir.

Midpalatal ve posterior genişlik miktarı gruplar arası değerlendirildiğinde istatistiksel olarak anlamlı fark, tek taraflı dudak damak yarıklı grubu ile izole damak yarığı grubu arasında bulunmuştur. Tek taraflı dudak damak yarıklı bireylerin genişlik miktarları palatal yarığı bulunan bireylere göre daha yüksektir.

\section{TARTIŞMA}

Bizim bu çalışmadaki amacımız Gaziantep ve çevre illere hizmet veren Gaziantep Üniversitesi Diş Hekimliği Fakültesi Ortodonti Anabilim Dalı'na tedavi amaçlı başvurmuş dudak damak yarıklı yeni doğan bebeklerin cinsiyet ve yarık miktarına göre dağılım düzeyini ortaya çıkarmak ve gurupların birbirleriyle olan ilişkilerini incelemektir.

Dudak damak yarıklı bireylerin görülme sıklığını rapor eden farklı araştırmalar bulunmaktadır. Turner ve ark. (1998) dünyada en fazla Hint ve doğu topluluklarında $(\% 0,2-0,3)$ görüldüğünü rapor etmişlerdir. McDonell ve ark. (2008) yaptığı bir çalışmada İrlanda toplumunda bu değer \%0,16 olarak bulunmuşken Pedersen ve ark. (2002) Danimarka toplumunda bu oranı $\% 0,23$ olarak bulmuşlardır. Ülkemizde de bu konuda yapılan araştırmalardan biri de Tunçbilek ve ark. (1999) tarafından ele alınmıştır. Bu araştırmacılar 1999 yılında yaptıkları çalışmaya göre dudak ve/veya damak yarığı görülme sıklığını \%0.095 olarak bildirmişlerdir. Tomatir ve ark. (2009) da 2000 ila 2004 yılları arasında yaptıkları retrospektif çalışmada Türkiye'de dudak - damak yarıkı doğum oranını $\% 0,055$ olarak belirtmişlerdir.

Dudak damak yarıklı hastalara yapılan tedaviler incelendiğinde, bu konuda daha önceki yapılan çalışmalarda pasif plak kullanılması veya yarık segmentlerin erken dönemde birbirine yaklaştırıması işleminin yarık genişliği miktarında azalmaya sebep olduğu sonucuna varılmıştır. Huddart (1979) yaptığı bir çalışmada plak kullanan ve plak kullanmayan yarıklı bireylerden oluşan deney gruplarında ve sağlıklı bireyden oluşan kontrol grubunda bireyler birkaç günlükken ve dördüncü ay sonunda iken ölçümler yapmış ve sonuçlarını karşılaştırmıştır. Yarık genişliği miktarının plak kullanan grupta $4.64 \mathrm{~mm}$, kullanmayan grupta ise $1.15 \mathrm{~mm}$ azaldığı sonucuna varmıştır. Bajramı ve ark (2004) tarafından yapılan başka bir çalışmaya göre de üç aylık pasif Hotz plağı kullanımının yarık genişliği miktarında anlamlı düzeyde azalmaya sebep olduğu sonucuna varılmıştır. Yağcı ve Uysal (2007) In tek taraflı yarıklı bireylerde nazoalveoler şekillendirme yönteminin yarık segmentler ve alveol genişliği üzerine etkilerini incelemek amacıyla yaptıkları çalışmada plak kullanımının yarık segmentler, arka ve orta alveoler genişlikler üzerinde olumlu etkilerinin olduğu belirlenmiştir. Pai ve ark. (2005), dudak damak yarığı bulunan yenidoğan bebekler ile yaptıkları çalışmada 3-4 ay sonunda yarık miktarında ortalama $5.8 \mathrm{~mm}$ azalma gözlemlemişlerdir. Bu sonuçlardan yola çıkarak çalışmamızda yarık genişliğinin azaltılması amacıyla yenidoğan dudak damak yarıklı bireylerden silikon esaslı ölçü maddesi kullanılarak ölçü alınmış ve elde edilen modeller üzerinde pasif Hotz plağı yapılmıştır.

Chiu ve ark. (2011) yeni doğanlardaki geniş yarık hattının retrüziv bir maksillaya sebep olduğunu savunmuş olup bu bulgu Liao ve ark. (2010) tarafından da desteklenmiştir. Parwaz ve ark. (2009) tek taraflı dudak damak yarığı ve damak yarığı bulunan hastalarda palatoplasti öncesi dental modeller üzerinde yaptıkları ölçümlerle ortalama 12.6 hafta sonrasında oluşan fistül formasyonunu karşılaştırmışlardır. $15 \mathrm{~mm}$ ve daha fazla yarığı bulunan hastalarda fistül formasyon riskinin anlamlı olarak arttığını görmüşlerdir. Yapılan araştırmalar, dudak damak yarıklarının erkeklerde kızlardan 2 kat fazla görüldüğünü ortaya koymuştur (Gorlin ve ark 1964). Lokalize damak yarıkları ise kızlarda daha fazladır ve tek taraflı yarıkların \%70'inin sol tarafta olduğu gözlenmiştir (Gorlin ve ark 1964). Sol taraflı olguların erkeklerde, sağ taraflı olguların ise kızlarda daha fazla olduğu ve tek taraflı olguların çift taraflılara göre daha çok görüldüğü rapor edilmiştir (Kaufman 1991). Çalışmamız sonuçlarında da daha öncekilerle uyumlu olacak şekilde tek ve çift taraflı dudak damak yarıkları erkeklerde, izole damak yarıkları ise kızlarda daha çok görüldü.

Gruplardan en düşük birey sayısının yarık grubunda olması sonucu Tunçbilek ve ark. (1999) nın yaptığı çalışmadaki izole damak insidansının (binde 0.5) diğer yarıklara göre daha düşük olması sonucuyla benzerdir. Anterior yarık genişliği miktarı çift taraflı dudak damak yarıklı bireylerde tek taraflı bireylerden, midpalatal genişliğin ve posterior palatal genişliğin ise tek taraflı yarıklı bireylerde daha fazla olduğu görüldü.

Kliniğimize en erken başvuran grubun çift taraflı dudak damak yarıklı bireyler, en geç başvuran grubun ise izole damak yarıklı bireyler olduğu tespit edildi. $\mathrm{Bu}$ durumun ailenin farketmesi ve beslenememe şikayeti oluşturma durumu ile ilgili olduğu düşünüldü.

Önceki yapılan çalışmalar dudak ve çevre dokuların şekillendirilmesi işleminin (nasal molding) pasif Hotz 
plağı kullanımına göre daha olumlu sonuçlar verdiğini göstermiştir. Göyenç ve Karadede (1993) yaptıkları çalışma ile erken dönemde kullanılan pasif plakların maksillanın gelişimini engellediği için uzun dönem çapraz kapanış riskini arttırdığı sonucuna varmışlardır. Huddart (1979) yaptığı bir çalışmada plak kullanan ve plak kullanmayan yarıklı bireylerden oluşan deney gruplarında ve sağlıklı bireyden oluşan kontrol grubunda, bireyler birkaç günlükken ve dördüncü ay sonunda iken ölçümler yapmış ve posterior ark genişliği miktarının artışının sağlıklı bireylerde $4.88 \mathrm{~mm}$, plak kullanmayan yarıklı bireylerde $3.89 \mathrm{~mm}$, plak kullanan yarıklı bireylerde ise $0.75 \mathrm{~mm}$ olduğunu rapor etmiştir. Bu sebeple maksiler arkın posterior gelişimi açısından pasif Hotz plağı yerine nazoalveoler molding apareylerinin kullanılmasının daha uygun olduğu sonucuna varılmıştır.

\section{ÖNERİLER}

Çalışmamı Gaziantep ve çevresindeki illerden fakültemize başvuran dudak damak yarıklı bireylerin cinsiyetleri, yaşları ve yarık boyutları ile ilgili analiz sonuçlarını göstermektedir. Gaziantep Üniversitesi Diş Hekimliği Fakültesi Ortodonti A.D da tedavi gören dudak damak yarıklı bireyler için, tek ve çift taraflı dudak damak yarıkları erkeklerde, izole damak yarıkları ise kızlarda daha çok görülmüştür. Anterior yarık genişlik miktarı en fazla çift taraflı dudak damak yarığı, midpalatal yarık genişlik miktarı tek taraflı dudak damak yarığı, posterior yarık genişliği miktarı ise tek taraflı dudak damak yarığı grubunda fazla bulunmuştur.

\section{Yeni doğan dudak damak yarıklı bebeklerin alçı modellerinin değerlendirilmesi}

Amaç: Dudak ve damak yarıkları baş-boyun bölgesinin sık görülen konjenital malformasyonları arasındadır. Bu çalışmada Gaziantep Üniversitesi Diş Hekimliği Fakültesi Ortodonti Anabilim Dalı'nda tedavi edilen dudak damak yarıkı hastalarının cinsiyet, yaş, yarık tipi, anterior yarık genişliği, midpalatal ve posterior palatal genişliklerine göre değerlendirilmesi amaçlanmıştır.

Gereç ve Yöntemler: Çalışmada kliniğimize gelen 39 dudak damak yarıklı hastanın kayıtları kullanıldı ve yaş, cinsiyet, yarık tipleri değerlendirildi. Analiz için alçı modeller üzerinde ölçümler yapıldı. Kullanılan referans noktaları; c, c' noktaları (kaninler bölgesi), t, t' noktaları (tüber noktaları), g, g' noktaları (c ve t noktaları arası mesafenin orta noktası) olarak belirlendi.

Bulgular: Çalışmaya dâhil edilen bireylerin \%24ü $(n=9)$ çift taraflı dudak damak yarıklı, \%20si $(n=8)$ izole damak yarıklı, \%56sı $(n=22)$ tek taraflı dudak damak yarıklı idi. Çift taraflı dudak damak yarıklı bireylerin yaş ortalaması $24.33 \pm 24.69$ gün, izole damak yarıkı bireylerin yaş ortalaması $68.37 \pm 58.04$ gün, tek taraflı dudak damak yarıklı bireylerin yaş ortalaması ise $31 \pm 30.11$ gündü. Çift taraflı dudak damak yarıklı bireylerin \%66.7si $(n=6)$ erkekti. Grubun anterior yarık genişliği ortalama olarak 13.23 \pm 3.06 , midpalatal genişliği 32.67 \pm 3.58 , postpalatal genişliği 29.25 \pm 2.78 $\mathrm{mm}$ idi. İzole damak yarıkı bireylerin \%37.5'i (3kişi) erkekti. Grubun anterior yarı genişliği bulunmamaktaydı. Midpalatal yarık genişliği $30.71 \pm 2.11$, postpalatal genişliği $27.17 \pm 2.42 \mathrm{~mm}$ idi. Unilateral yarıklı bireylerin \%54.5i (12kişi) erkekti. Grubun anterior yarık genişliği $10.14 \pm 3.12$, midpalatal genişlik 35.74 \pm 3.05 , postpalatal genişlik ise $31.35 \pm 3.22 \mathrm{~mm}$ idi.

Sonuç: Tek ve çift taraflı dudak damak yarıkları erkeklerde, izole damak yarıkları ise kızlarda daha çok görüldü. Anterior yarık genişliği miktarı çift taraflı dudak damak yarıklı grupta tek taraflı dudak damak yarıklı gruptan daha fazla olduğu görüldü. Ancak midpalatal genişliğin ve posterior palatal genişliğin tek taraflı dudak damak yarıklı bireylerde daha fazla olduğu görüldü. Kliniğimize en erken başvuran grubun çift taraflı dudak damak yarıklı bireyler, en geç başvuran grubun ise izole damak yarıklı bireyler olduğu tespit edildi. Kliniğimize başvuran, gerek Hotz plağı gerek nazal molding aygıtlarıyla tedavilerine başlanan hastaların uzun dönem takiplerinin yapılarak başlangıç değerleriyle karşılaştırılması düşünüldü.

ANAHTAR KELIMELER

Ortodonti, yarık damak, yarık dudak 


\section{KAYNAKLAR}

Bajramı AK, Işıksal E, Doğan S. Unilateral komple dudak damak yarıklarında erken tedavi yaklaşımlarının üst çene gelişimi üzerine etkisinin incelenmesi. Türk Ortodonti Dergisi 2004:17:27- 46.

Barbara C.M. Oosterkamp, Wicher J. van der Meer, Majelle Rutenfrans, Pieter U.Dijkstra, Reliability of Linear Measurements on a Virtual Bilateral Cleft Lip and Palate. Cleft Palate-Craniofacial Journal. 2006: 43:5

Chiu YT, Liao YF, Chen PK. Initial cleft severity and maxillary growth in patients with complete unilateral cleft lip and palate. Am J Orthod Dentofacial Orthop. 2011;140:189-195.

Cornel MC, Spreen JA, Meijer I, et al. Some epidemiological data on oral clefts in the Northern Netherlands, J Craniomaxillofac Surg 1988:20:147

Gorlin RJ, Pindbrog JJ. Syndromes of the Head and Neck. McGraw-Hill, New York 1964:2:14.

Göyenç Y, Karadede i. Unilateral dudak damak yarıklı bebeklerde "Hotz" tipi pasif preoperatif apareyin etkileri. Türk Ortodonti Dergisi 1993:6:8289.

Heliovaara A, Pere A, Ranta R. One-stage closure of isolated cleft palate with the Veau-Wardill-Kilner $V$ to $Y$ pushback procedure or the Cronin modification. II. Height, weight and comparison of dental arches. Scand J Plast Reconstr Surg Hand Surg. 1994;28:5562.

Hellquist R, Skoog T. The influence of primary periosteoplasty on maxillary growthand deciduous occlusion in cases of complete unilateral cleft lip and palate. A longitudinal study from infancy to the age of 5. Scand J Plast Reconstr Surg. 1976:10:197-208.

Honda Y, Suzuki A, Ohishi M, Tashiro $H$. Longitudinal study on the changes of maxillary arch dimensions in Japanese children with cleft lip and/or palate: infancy to 4 years of age. Cleft Palate Craniofac J. 1995; 32:149-155.

Huddart AG. Presurgical changes in unilateral cleft palate subjects. Cleft Palate J 1979:16:147-157.
Johnson N, Williams A, Singer S, Southall P, Sandy $\mathrm{J}$. Initial cleft size does not correlate with outcome in unilateral cleft lip and palate. Eur $J$ Orthod. 2000;22:93-100.

Kaufman FL. Managing the cleft lip and palate patients. Pediatr Clin North Am 1991, 38: 535-545.

Liao YF, Prasad NK, Chiu YT, Yun C, Chen PK. Cleft size at the time of palate repair in complete unilateral cleft lip and palate as an indicator of maxillary growth. Int J Oral Maxillofac Surg. 2010;39:956-961.

Lohmander-Agerskov A, Friede H, Soderpalm E, Lilja J. Residual clefts in the hardpalate: correlation between cleft size and speech. Cleft Palate Craniofac J. 1997;34:122-128.

McDonnell R, Owens $M$, Delany C, Earley $M$, McGillivary A, Orr DJ et al. Epidemiology of Orofacial Clefts in the East of Ireland in the 25-Year Period 1984-2008. The Cleft Palate-Craniofacial Journal, 2013, 10.1597/11-299

Pai BC, Ko EW, Huang CS, Liou EJ: Symmetry of the nose after presurgical nasoalveolar molding in infants with unilateral cleft lip and palate: a preliminary study. Cleft Palate Craniofac J 2005; 42: 658-663.

Parwaz MA, Sharma RK, Parashar A, Nanda V, Biswas G, Makkar S. Width of cleft palate and postoperative palatal fistula--do they correlate? J Plast Reconstr Aesthet Surg. 2009; 62:1559-1563.

Pedersen GSt, Pedersen DA, Mortensen LH, Andersen A-MN, Christensen K. Ethnic Variation in Oral Cleft Occurrence in Denmark, The Cleft PalateCraniofacial Journal, 2002:10:2:14-18.

Peltomaki T, Vendittelli BL, Grayson BH, Cutting CB, Brecht LE. Associations between severity of clefting and maxillary growth in patients with unilateral cleft lip and palate treated with infant orthopedics. Cleft Palate Craniofac J. 2001;38:582-586.

Persson C, Elander A, Lohmander-Agerskov A, Soderpalm E. Speech outcomes in isolated cleft palate: impact of cleft extent and additional malformations. Cleft Palate Craniofac J. 2002;39:397408. 
Reiser,E. Cleft Size and Maxillary Arch Dimension in Unilateral Cleft Lip and Palate and Cleft Palate.Acta Univesitatis Upsaliensis. Digital Comprehensive Summaries of Uppsala Dissertations from the Faculty of Medicine. 2011:722.74pp. Uppsala ISBN 978-91-5548213-8.

Reiser E, Skoog V, Gerdin B, Andlin-Sobocki A. Association between cleft size and crossbite in children with cleft palate and unilateral cleft lip and palate. Cleft Palate Craniofac J. 2010:47(2):175-81

Seckel NG, van der Tweel I, Elema GA, Specken TF. Landmark positioning on maxilla of cleft lip and palate infant--a reality? Cleft Palate Craniofac J. 1995:32:434441.

Shah CP, Wong D. Management of children with cleft lip and palate. 1980 CMAJ 122:19-24

Sillman J. Dimensional changes of the dental arches: Longitudinal study from birth to 25 years. Am J Orthod. 1964;50:824-84.29.

Sokucu O, Nalcacı R, Ozturk F, Toy S. Dudak Damak Yarıklı Bireylerin Kendini-Kabul Düzeylerinin Değerlendirilmesi. Cumhuriyet Dental Journal 2008: 11:1

Tomatir A, Demirhan H, Sorkun H, Köksal A, Özerdem F, Cilengir N. Major congenital anomalies: a five-year retrospective regional study in Turkey. Genetics and Molecular Research 2009:8:19-27.

Tunçbilek G. Dudak- damak yarıklarında kalıtım ve epidemiyoloji. In: Erk Y, Özgür F, eds. Dudak damak yarıkları. Ankara: Işkur Matbaacılık Ltd Şti; 1999: s.7-13

Turner SR, Rumsey N, Sandy JR. Psychological aspects of cleft lip and palate. Eur J Orthod 1998; 20: 407-415.

Yağcı A, Uysal T. Tek taraflı dudak-damak yarığına sahip bebeklerde nazoalveoler şekillendirme yönteminin yarık segmentler ve alveol genişlikleri üzerine etkilerinin değerlendirilmesi. Sağlık Bilimleri Dergisi (Journal of Health Sciences) 2007:16:1-10.

Yazışma Adresi:

Merve Göymen

Gaziantep Üniversitesi Diş Hekimliği Fakültesi

Ortodonti AD 27310 Gaziantep

Tel: +90 5054767651

E-mail: mervegoymen@gmail.com 